\title{
INFLAMMATION AT THE CROSSROADS: THE COMBINED EFFECTS OF COVID-19, AGEING, AND AIR POLLUTION
}

\author{
P.J. MARTIN ${ }^{1}$, S. BILLET ${ }^{1}$, Y. LANDKOCZ ${ }^{1}$, B. FOUGËRE ${ }^{2,3}$ \\ 1. Univ. Littoral Côte d'Opale, UR 4492, UCEIV, Unité de Chimie Environnementale et Interactions sur le Vivant, SFR Condorcet FR CNRS, F-59140 Dunkerque, France; 2 . Division of \\ Geriatric Medicine, Tours University Hospital, Tours, France; 3. Éducation, éthique, santé (EA 7505), Tours University, Tours, France. \\ Corresponding author: Dr. Sylvain Billet, Univ. Littoral Côte d'Opale, UR 4492, UCEIV, Maison de la Recherche en Environnement Industriel 2, 189A, Avenue Maurice Schumann, \\ 59140 Dunkerque, France. Phone: +33-3 2823 76 41, E-mail: sylvain.billet@univ-littoral.fr
}

\begin{abstract}
The global COVID-19 pandemic has highlighted different vulnerability profiles among individuals. With the highest mortality rate, the elderly are a very sensitive group. With regard to the main symptoms, a failure of the respiratory system, associated with deregulation of the immune system, has been observed. These symptoms may also be encountered in chronic exposure of susceptible populations to air pollution, including exacerbation of the inflammatory response. Is there a relationship between age, pollution exposure and the severity of COVID-19? Although it is unclear how these parameters are related, the same pathways can be activated and appear to find a common mechanism of action in inflammation.
\end{abstract}

Key words: Inflammation, COVID-19, ageing, air pollution.

\section{Introduction}

Acute inflammation is an immediate, rapid response to an attack on the body. When as is usually the case the inflammation is not excessive, it resolves itself after the harmful agent or pathogen has been destroyed or eliminated. Essentially, acute inflammation comprises four phases (1): homing of immune cells to the tissue; immune cell differentiation and activation in situ; a "switch» to suppressive cells; and a return to homeostasis. In contrast, chronic inflammation persists over time, does not resolve itself fully, and may damage the tissues concerned. It is known that both acute and chronic lung inflammation contributes to the harmful effects of inhaled pathogens or toxicants, and constitutes a pathogenic pathway in many lung diseases (2). Lung inflammation is characterized by two successive steps. Firstly, activated macrophages, neutrophils and T lymphocytes infiltrate into the airways. Secondly, chemokines, oxygen radicals, proteases and pro-inflammatory cytokines are produced. Cytokines include interleukin 6 (IL-6), tumor necrosis factor alpha (TNF $\alpha)$, and interleukin 12 (IL-12) (2, 3 ). The lung damage caused by excessive acute inflammation can lead to pulmonary fibrosis and can interfere with gas exchanges. Unresolved lung damage and chronic inflammation are frequently observed in acute respiratory distress syndrome, cystic fibrosis, chronic obstructive pulmonary disease (COPD), and asthma. When inflammation cannot be resolved properly, its characteristics change as more macrophages are recruited and the adaptive system starts to respond. In the worst cases, this inflammation can evolve into an often lethal cytokine storm (also referred to as «cytokine shock» or «cytokine release syndrome»). Although the links between ageing, atmospheric pollution and COVID-19 are difficult to pinpoint, there is Received October 9, 2020 Accepted for publication December 11, 2020 evidence for common pathways based on deregulation of inflammation in particular. Despite the increasing number of publications on the emerging disease COVID-19, only one author has considered the possibility of a cross impact between these different factors and focused its analysis on the treatment of inflammation and thrombotic states (4). Therefore we propose a review that considers the mechanistic aspect that would underlie this common pathway.

\section{Inflammation and COVID-19}

A cytokine storm is a massive inflammatory phenomenon in which cytokine production is both excessive and self-sustaining (5). This phenomenon has been described in a broad range of infectious and non-infectious diseases, including some human respiratory tract diseases caused by coronaviruses (6). With regard to coronaviruses that have emerged in recent years, it has been shown that infection by Severe Acute Respiratory Syndrome (SARS) coronaviruses can result in the massive production of TNF $\alpha$, IL- 6 and IL-8, and that infection by Middle East Respiratory Syndrome (MERS)-related coronavirus leads to the production of IL-6, IL-1 $\beta$, and IL-8 (6). In severe cases of COronaVIrus Disease 2019 (COVID-19), elevated blood levels of IL-1 $\beta$, IL-6, IL-8, IL-12, interferon gamma (IFN- $\gamma$ ), granulocyte-macrophage colony-stimulating factor (GM-CSF) and TNF $\alpha$-induced cytokines have been evidenced (7). Furthermore, lymphopenia is a universal feature in patients with COVID-19, and an analysis of T lymphocyte subsets shows a significant decrease in CD4+ and CD8+ T cells counts. Among the various cytokines involved in the cytokine storm, IL-6 and GM-CSF appear to have the most harmful effects in the exacerbation of inflammation, with (among other things) high blood pressure, tachycardia progressing to 


\section{THE COMBINED EFFECTS OF COVID-19, AGEING, AND AIR POLLUTION}

bradycardia, hypoxia, and pulmonary fibrosis. The subsequent acute respiratory distress syndrome can lead to multi-organ failure and death. Even at the beginning of the pandemic, physicians suspected that a cytokine storm was involved in the expression of the most severe forms of COVID-19.

\section{Inflammation and ageing}

Ageing and age-related diseases share some basic mechanistic components, many of which result in inflammation. The development of a chronic, sterile, low-grade inflammatory state contributes to the pathogenesis of age-related diseases (8). Biological ageing is the result of an accumulation of genetic and epigenetic changes that lead progressively to cell damage, impaired tissue function, vulnerability to stressors, low physiological reserves, and a more limited ability to maintain homeostasis (9). Although a single mechanism for the causes and progression of biological ageing has not been established, the most frequently cited etiologies are redox stress, immune system deregulation, mitochondrial dysfunction, glycation, hormonal changes, epigenetic modifications, and telomere attrition (10). The environment may also have a role in biological ageing by disrupting the homeostatic balance (11). Even though the involvement of the afore-mentioned factors is widely accepted, the cellular and molecular details of biological ageing have yet to be determined. Some studies have suggested that chronic inflammation accelerates biological ageing (12). Although the immune response that is characteristic of acute inflammation subsides within a few days, chronic inflammation is characterized by the release of elevated levels of pro-inflammatory cytokines in response to physiological and environmental stressors. This essentially shifts the immune system into a state of low-level activation (8). The chronically active immune system activity associated with advancing age has been termed "inflammatory ageing" or "inflammaging" (13-15). Although the detailed mechanisms have yet to be characterized, the pro-inflammatory cell phenotype associated with the upregulation of the inflammatory response with age has been found to have a role in the initiation and progression of age-related diseases such as cardiovascular disease, type II diabetes, frailty, sarcopenia, Alzheimer's disease, osteoporosis, and cancer $(16,17)$.

\section{Ageing and COVID-19}

The COVID-19 pandemic is having a major impact on populations worldwide. Although all age groups are at risk of contracting COVID-19, older adults are the most at risk of severe disease as a result of age-related physiological changes and possible pre-existing conditions (18-20). A very recent report showed that the mean \pm Standard Deviation (SD) age of patients with severe and critical forms of COVID-19 was $59.38 \pm 16.54$, with more than $50 \%$ over the age of 60 and a predominance of males $(64.60 \%)$ (21). Similarly, over $50 \%$ of the deceased patients are aged 60 or over (21). A study published in The Lancet Infectious Diseases estimated that the proportion of infected people likely to be hospitalized increases with age, up to a maximum of $18.4 \%$ [95\% confidence interval: 11.0-37.6] among people aged 80 or over (22). In Wuhan (China), patients over 65 years of age had a greater number of co-morbidities at baseline and displayed more severe symptoms (including multisystem failure and death) than younger patients did (23). Eight out of 10 deaths reportedly occur in people with at least one co-morbidity - particularly cardiovascular disease, hypertension, and diabetes, but also a range of other pre-existing chronic conditions that often appear with age (24). One explanation for this may be that immunosenescence in the older adult is associated with greater susceptibility to infectious disease (25). Hence, "inflammaging" can accentuate the harmful effects of SARS-CoV-2 infection. Conversely, an acute SARS-CoV-2 infection may worsen any chronic, agerelated, pro-inflammatory conditions. When combined with immune senescence and the age- and sex-specific distributions of angiotensin-converting enzyme II (ACE 2) in the airway epithelium, this situation may accentuate the antiviral response to inflammation (53).

\section{Air pollution and inflammation}

As mentioned above, environmental factors can have a role in the occurrence of disease. Air pollution constitutes one of the best known environmental risk factors, and is thought to cause about 3.3 million premature deaths per year worldwide (26). Air pollution is composed of particles, gases, and bioaerosols containing pollen and airborne microorganisms (viruses, bacteria, fungi, spores, etc.). A large number of studies have shown that exposure to air pollutants is associated with cardiovascular adverse events (27). Inflammation is very frequently cited as a cause of cardiovascular disease; it is not always associated with an infection and may be triggered by other "danger signals" referred to collectively as danger-associated molecular patterns. These patterns come from damaged or altered cells (e.g. cancer cells), chemical irritants (e.g. pollutants) and even physical disturbances (e.g. mechanical forces). This sterile inflammation may be associated with oxidative conditions that are potentially triggered or exacerbated by exposure to air pollution $(28,29)$. Oxidative stress is generally defined as a chronic shift in the intracellular redox balance towards oxidative conditions. It is initiated by reactive oxygen species (ROS) and reactive nitrogen species, and has a central role in many adverse health effects - particularly in the respiratory tract (3). High levels of ROS may exceed the cells' antioxidant capacity and trigger a cascade of events closely associated with inflammation and, at higher concentrations, apoptosis and genetic and epigenetic alterations. Thus, increased activation of the transcription factor nuclear factor - kappa B by oxidative stress is involved in the regulation of a large number of genes controlling the inflammatory 


\section{THE JOURNAL OF FRAILTY \& AGING}

response (30). Furthermore, environmental exposure has been shown to increase levels of pro-inflammatory cytokines (e.g. IFN $\gamma$, IL 6, IL 8, IL 12, IL-1 $\beta$, and TNF $\alpha$ ) (31). The release of these cytokines into the lung and the peripheral blood leads to systemic inflammation and immune disorders (32-35). Exposure to air pollutants also increases the numbers of immune cells (neutrophils, lymphocytes and macrophages) that infiltrate into the lungs (36). Neutrophil recruitment to the lungs increases the inflammatory response and the resulting damage. During this pollutant-induced phase of inflammation, the number of macrophages also increases via differentiation of the infiltrated monocytes into M1 macrophages (37). Chronic exposure to pollutants such as fine particles $\left(\mathrm{PM}_{25}\right)$ can raise levels of inflammatory markers such as $\mathrm{C}$-reactive protein, which is directly involved in the development of cardiovascular disease (38). This can also lead to the development of chronic inflammatory diseases, such as asthma and COPD (39).

\section{Air pollution and COVID-19}

In recent years, a large number of research groups have examined the interaction between airborne particles and viruses. For example, the risk of pneumonia caused by respiratory syncytial virus (RSV) in children is increased by the penetrate of particulate pollutants $\left(\mathrm{PM}_{2.5}\right.$ and $\left.\mathrm{PM}_{10}\right)$ deep into the respiratory tract (40). Similar results have been reported for measles, the incidence of which was significantly amplified by an increase in $\mathrm{PM}_{2.5}$ of $10 \mu \mathrm{g} / \mathrm{m}^{3}$ (4). In Europe, the epidemiological data show that the regions known to be the most polluted by $\mathrm{PM}_{2.5}, \mathrm{PM}_{10}$, and $\mathrm{NO}_{2}$ (Lombardy and the Po valley in northern Italy) were also the most affected by the spread of SARS-CoV-2 $(42,43)$. In the United States, the results of an ecological study of $98 \%$ of the American population (currently under review) suggested a strong association between elevated particulate matter concentrations and mortality rates due to COVID-19 (44). A slight increase in long-term exposure to $\mathrm{PM}_{2.5}$ leads to a large increase in mortality associated with COVID 19. A study conducted in 120 Chinese cities determined a significant association between a $10 \mu \mathrm{g} / \mathrm{m}^{3}$ increase in $\mathrm{PM}_{2.5}, \mathrm{PM}_{10}, \mathrm{NO}_{2}$ and $\mathrm{O}_{3}$ and the number of new positive cases $(2.24 \%, 1.76 \%, 6.94 \%$ and $4.76 \%$, respectively) (45). Thus, several research groups have looked at whether or not the presence of SARS-COV-2 RNA on particulate matter in outdoor air samples is a potential early indicator of the spread of COVID-19 (43). Thus, an RT-qPCR analysis of RNA extracted from $34 \mathrm{PM}_{10}$ samples showed the presence of the E gene (which is specific for SARS-like viruses) and RdRP genes (which are highly specific for SARSCoV-2) (46). However, it is not known whether virus-carrying particles are contagious. There are several possible explanations for the impact of air pollution exposure on the severity of COVID-19. One of them would be that chronic exposure to air pollution has been implicated in many cardiopulmonary diseases. The oxidative stress due to exposure to pollutants leads to the production of free radicals, which damage the respiratory system and reduce resistance to viral and bacterial infections. Pollutants might both directly impair the lungs' ability to eliminate pathogens and indirectly exacerbate any underlying cardiovascular or pulmonary diseases $(47,48)$. The presence of co-morbidities leads to inflammation, and pollutant-induced oxidative stress and cell damage may worsen the prognosis $(49,50)$. Chronic exposure to $\mathrm{PM}_{2.5}$ leads to the overexpression of alveolar ACE-2 receptors; this increase might amplify the viral load, deplete ACE-2 receptors, and weaken host defenses. Moreover, $\mathrm{NO}_{2}$ acts as a pro-oxidant by depleting the anti-oxidant pool and thus impairing tissue defenses (especially phagocytic activity) and increasing inflammation and cell damage. Exposure to $\mathrm{NO}_{2}$ causes a severe form of COVID-19 in ACE-2-depleted lungs and thus worsens the outcome (51).

\section{Inflammation at the crossroads?}

The most severe forms of COVID-19 increase in prevalence with age; as described above, the oldest people have the highest mortality rate and the greatest risk of cytokine shock. The analysis of patients with COVID-19 patients shows that younger individuals are less affected by the disease (52). This can be explained by the immature immune system in children, who are much less affected by this epidemic $(53,54)$. Moreover, it is now well known that the effects of air pollution are exacerbated among the elderly, with effects on the immune, respiratory and cardiovascular systems $(55,56)$. The cytokine storm sometimes seen in COVID-19 is particularly damaging for older adults (57); in particular, myocardial injury can be amplified by exposure to particulate pollutants. Indeed, $\mathrm{PM}_{2.5}$ exposure is known to increase the risk of heart diseases like as acute myocardial injury and infarction (58). One of SARS-CoV2 's first targets is the respiratory tract, which is continuously exposed to external stressors. Activation of the immune system in the lungs during exposure to gaseous or particulate pollutants has already been demonstrated - especially in sensitive individuals like older adults (56). Moreover, the aggravation of chronic inflammatory respiratory diseases (e.g. asthma) by air pollution has been widely described $(59,60)$. Thus, COVID-19 may have more serious outcomes (e.g. cytokine shock) when the respiratory tract has already been sensitized by chronic exposure to air pollution.

\section{Conclusion}

In conclusion, one can legitimately hypothesize that COVID19 is synergized by age and exposure to air pollution via an exacerbation of inflammation. Further research is needed to determine the infectious potential of SARS-CoV-2 on particulate matter and the latter's potential role in spreading disease. Public health policies in populations such as older adults (e.g. reducing their exposure to atmospheric pollution) 


\section{THE COMBINED EFFECTS OF COVID-19, AGEING, AND AIR POLLUTION}

may now be especially important. Furthermore, disparities in socioeconomic factors and elevated prevalences of diabetes, heart disease, and chronic airway diseases (e.g. lung cancer and COPD) are likely to accentuate the mortality rate among older populations (47). The presence of common pathways (including inflammation and repeated exposure to air pollutants) may have contributed to the disproportionate impact of COVID-19 on older adults.

\section{Conflict of interest: The authors report no conflict of interest.}

Author contributions: All the authors participated in the preparation of the manuscript, the search for publications and their analysis. The authors would like to thank David Fraser (Biotech Communication SARL) for his careful correction of the English language of the manuscript.

Sponsor's role: This research did not receive any specific grant from funding agencies in the public, commercial, or not.

\section{References}

1. Chen L, Deng H, Cui H, et al. Inflammatory responses and inflammation-associated diseases in organs. Oncotarget. 2017;9(6):7204-7218. doi:10.18632/oncotarget.23208

2. Wong J, Magun BE, Wood LJ. Lung inflammation caused by inhaled toxicants: a review. Int J Chron Obstruct Pulmon Dis. 2016;11:1391-1401. doi:10.2147/COPD. S106009

3. Gualtieri M, Ledoux F, Verdin A, Billet S, Martin PJ, Courcot D. Particulate Matte Physico-Chemical Characterization and in vitro Toxicological Effects. Airborne Particles: Origin, Emissions and Health Impacts, Nova Science Publishers, Prashant Kumar (Editor), University of Surrey, Guildford, GU2 7XH, UK. 2017:Chapter: 12.

4. Menendez JA. Metformin and SARS-CoV-2: mechanistic lessons on air pollution to weather the cytokine/thrombotic storm in COVID-19. Aging (Albany NY). 2020;12(10):8760-8765. doi:10.18632/aging.103347

5. Tisoncik JR, Korth MJ, Simmons CP, Farrar J, Martin TR, Katze MG. Into the eye of the cytokine storm. Microbiol Mol Biol Rev. 2012;76(1):16-32. doi:10.1128 MMBR.05015-11

6. Yao Z, Zheng Z, Wu K, Junhua Z. Immune environment modulation in pneumonia patients caused by coronavirus: SARS-CoV, MERS-CoV and SARS-CoV-2. Aging (Albany NY). 2020;12(9):7639-7651. doi:10.18632/aging.103101

7. Li K, Hao Z, Zhao X, Du J, Zhou Y. SARS-CoV-2 infection-induced immune responses: friends or foes? Scand J Immunol. Published online May 23, 2020:e12895. doi:10.1111/sji.12895

8. Baylis D, Bartlett DB, Patel HP, Roberts HC. Understanding how we age: insights into inflammaging. Longev Healthspan. 2013;2(1):8. doi:10.1186/2046-2395-2-8

9. Burton DGA. Cellular senescence, ageing and disease. Age (Dordr). 2009;31(1):1-9 doi:10.1007/s11357-008-9075-y

10. Kirkwood TB. The nature and causes of ageing. Ciba Found Symp. 1988;134:193-207.

11. Fougère B, Vellas B, Billet S, Martin PJ, Gallucci M, Cesari M. Air Pollution modifies the association between successful and pathological aging throughout the frailty condition. Ageing Res Rev. 2015;24(Pt B):299-303. doi:10.1016/j.arr.2015.09.004

12. Ren J-L, Pan J-S, Lu Y-P, Sun P, Han J. Inflammatory signaling and cellular senescence. Cell Signal. 2009;21(3):378-383. doi:10.1016/j.cellsig.2008.10.011

13. Franceschi C, Garagnani P, Parini P, Giuliani C, Santoro A. Inflammaging: a new immune-metabolic viewpoint for age-related diseases. Nature Reviews Endocrinology. 2018;14(10):576-590. doi:10.1038/s41574-018-0059-4

14. Franceschi C, Capri M, Monti D, et al. Inflammaging and anti-inflammaging: a systemic perspective on aging and longevity emerged from studies in humans. Mech Ageing Dev. 2007;128(1):92-105. doi:10.1016/j.mad.2006.11.016

15. Freund A, Orjalo AV, Desprez P-Y, Campisi J. Inflammatory networks during cellular senescence: causes and consequences. Trends Mol Med. 2010;16(5):238-246. doi:10.1016/j.molmed.2010.03.003

16. Zhang X, Zhang G, Zhang H, Karin M, Bai H, Cai D. Hypothalamic IKKbeta/ NF-kappaB and ER stress link overnutrition to energy imbalance and obesity. Cell 2008;135(1):61-73. doi:10.1016/j.cell.2008.07.043

17. Cevenini E, Monti D, Franceschi C. Inflamm-ageing. Curr Opin Clin Nutr Metab Care. 2013;16(1):14-20. doi:10.1097/MCO.0b013e32835ada13

18. Petrilli CM, Jones SA, Yang J, et al. Factors associated with hospital admission an critical illness among 5279 people with coronavirus disease 2019 in New York City: prospective cohort study. BMJ. 2020;369:m1966. doi:10.1136/bmj.m1966

19. Ouvrard C, Meillon C, Dartigues J-F, Tabue Teguo M, Avila-Funes JA, Amieva H. Psychosocioeconomic Precariousness and Frailty: The Respective Contribution in
Predicting Mortality. J Frailty Aging. 2019;8(1):42-47. doi:10.14283/jfa.2018.36

20. Andrew MK, Dupuis-Blanchard S, Maxwell C, et al. Social and societal implications of frailty, including impact on Canadian healthcare systems. J Frailty Aging. 2018;7(4):217-223. doi:10.14283/jfa.2018.30

21. Shi M, Chen L, Yang Y, et al. Analysis of clinical features and outcomes of 161 patients with severe and critical COVID-19: A multicenter descriptive study. J Clin Lab Anal. Published online June 2, 2020:e23415. doi:10.1002/jcla.23415

22. Verity R, Okell LC, Dorigatti I, et al. Estimates of the severity of coronavirus disease 2019: a model-based analysis. The Lancet Infectious Diseases. 2020;20(6):669-677. doi:10.1016/S1473-3099(20)30243-7

23. Chen T, Dai Z, Mo P, et al. Clinical characteristics and outcomes of older patients with coronavirus disease 2019 (COVID-19) in Wuhan, China (2019): a single-centered, retrospective study. J Gerontol A Biol Sci Med Sci. Published online April 11, 2020. doi:10.1093/gerona/glaa089

24. Wu Z, McGoogan JM. Characteristics of and Important Lessons From the Coronavirus Disease 2019 (COVID-19) Outbreak in China: Summary of a Report of 72314 Cases From the Chinese Center for Disease Control and Prevention. JAMA. 2020;323(13):1239-1242. doi:10.1001/jama.2020.2648

25. Oh S-J, Lee JK, Shin OS. Aging and the Immune System: the Impact of Immunosenescence on Viral Infection, Immunity and Vaccine Immunogenicity. Immune Network. 2019;19(6). doi:10.4110/in.2019.19.e37

26. Lelieveld J, Evans JS, Fnais M, Giannadaki D, Pozzer A. The contribution of outdoor air pollution sources to premature mortality on a global scale. Nature. 2015;525(7569):367-371. doi:10.1038/nature15371

27. Brook RD, Rajagopalan S, Pope CA, et al. Particulate matter air pollution and cardiovascular disease: An update to the scientific statement from the American Heart Association. Circulation. 2010;121(21):2331-2378. doi:10.1161/ CIR.0b013e3181dbece1

28. Connor AJ, Laskin JD, Laskin DL. Ozone-induced lung injury and sterile inflammation. Role of toll-like receptor 4. Exp Mol Pathol. 2012;92(2):229-235. doi:10.1016/j.yexmp.2012.01.004

29. Shen H, Kreisel D, Goldstein DR. Processes of Sterile Inflammation. J Immunol. 2013;191(6):2857-2863. doi:10.4049/jimmunol.1301539

30. Dagher Z, Garçon G, Billet S, et al. Role of nuclear factor-kappa B activation in the adverse effects induced by air pollution particulate matter (PM2.5) in human epithelia lung cells (L132) in culture. J Appl Toxicol. 2007;27(3):284-290. doi:10.1002/jat.1211

31. Tsai D-H, Riediker M, Berchet A, et al. Effects of short- and long-term exposures to particulate matter on inflammatory marker levels in the general population. Environ Sci Pollut Res Int. 2019;26(19):19697-19704. doi:10.1007/s11356-019-05194-y

32. Gu X, Chu X, Zeng X-L, Bao H-R, Liu X-J. Effects of PM2.5 exposure on the Notch signaling pathway and immune imbalance in chronic obstructive pulmonary disease. Environmental Pollution. 2017;226:163-173. doi:10.1016/j.envpol.2017.03.070

33. Wang Z, Zhao J, Wang T, Du X, Xie J. Fine-particulate matter aggravates cigarette smoke extract-induced airway inflammation via Wnt5a-ERK pathway in COPD. International Journal of Chronic Obstructive Pulmonary Disease. 2019; Volume 14:979-994. doi:10.2147/COPD.S195794

34. Dergham M, Lepers C, Verdin A, et al. Temporal-spatial variations of the physicochemical characteristics of air pollution Particulate Matter (PM2.5-0.3) and toxicological effects in human bronchial epithelial cells (BEAS-2B). Environmental Research. 2015;137:256-267. doi:10.1016/j.envres.2014.12.015

35. Manzano-León N, Serrano-Lomelin J, Sánchez BN, et al. TNF $\alpha$ and IL-6 Responses to Particulate Matter in Vitro: Variation According to PM Size, Season, and Polycyclic Aromatic Hydrocarbon and Soil Content. Environ Health Perspect. 2016;124(4):406 412. doi: $10.1289 / \mathrm{ehp} .1409287$

36. Wang $\mathrm{H}$, Song $\mathrm{L}, \mathrm{Ju} \mathrm{W}$, et al. The acute airway inflammation induced by PM2.5 exposure and the treatment of essential oils in Balb/c mice. Sci Rep. 2017;7:44256. doi: $10.1038 /$ srep44256

37. Goto $\mathrm{Y}$, Ishii $\mathrm{H}$, Hogg JC, et al. Particulate matter air pollution stimulates monocyte release from the bone marrow. Am J Respir Crit Care Med. 2004;170(8):891-897. doi:10.1164/rccm.200402-235OC

38. Ostro B, Malig B, Broadwin R, et al Chronic PM2.5 exposure and inflammation: determining sensitive subgroups in mid-life women. Environ Res. 2014;132:168-175. doi:10.1016/j.envres.2014.03.042

39. Alkoussa S, Hulo S, Courcot D, Billet S, Martin PJ. Extracellular vesicles as actors in the air pollution related cardiopulmonary diseases. Crit Rev Toxicol. Published online June 5, 2020:1-22. doi:10.1080/10408444.2020.1763252

40. Ye Q, Fu J-F, Mao J-H, Shang S-Q. Haze is a risk factor contributing to the rapid spread of respiratory syncytial virus in children. Environ Sci Pollut Res Int 2016;23(20):20178-20185. doi:10.1007/s11356-016-7228-6

41. Chen G, Zhang W, Li S, et al. Is short-term exposure to ambient fine particles associated with measles incidence in China? A multi-city study. Environ Res. 2017;156:306-311. doi:10.1016/j.envres.2017.03.046

42. Ogen $\mathrm{Y}$. Assessing nitrogen dioxide (NO2) levels as a contributing factor to coronavirus (COVID-19) fatality. Sci Total Environ. 2020;726:138605. doi:10.1016/j. scitotenv.2020.138605

43. Setti L, Passarini F, De Gennaro G, et al. Searching for SARS-COV-2 on Particulate Matter: A Possible Early Indicator of COVID-19 Epidemic Recurrence. Int J Environ Res Public Health. 2020;17(9). doi:10.3390/ijerph17092986 


\section{THE JOURNAL OF FRAILTY \& AGING}

44. Wu X, Nethery RC, Sabath BM, Braun D, Dominici F. Exposure to air pollution and COVID-19 mortality in the United States: A nationwide cross-sectional study. medRxiv. Published online April 27, 2020:2020.04.05.20054502. doi:10.1101/2020.04.05.20054502

45. Zhu Y, Xie J, Huang F, Cao L. Association between short-term exposure to air pollution and COVID-19 infection: Evidence from China. Sci Total Environ. 2020;727:138704. doi:10.1016/j.scitotenv.2020.138704

46. Setti L, Passarini F, De Gennaro G, et al. SARS-Cov-2RNA found on particulate matter of Bergamo in Northern Italy: First evidence. Environmental Research. 2020;188:109754. doi:10.1016/j.envres.2020.109754

47. Brandt EB, Beck AF, Mersha TB. Air pollution, racial disparities, and COVID-19 mortality. J Allergy Clin Immunol. Published online May 7, 2020. doi:10.1016/j. jaci.2020.04.035

48. Fattorini D, Regoli F. Role of the chronic air pollution levels in the Covid-19 outbreak risk in Italy. Environ Pollut. 2020;264:114732. doi:10.1016/j.envpol.2020.114732

49. Conticini E, Frediani B, Caro D. Can atmospheric pollution be considered a co-factor in extremely high level of SARS-CoV-2 lethality in Northern Italy? Environ Pollut. 2020;261:114465. doi:10.1016/j.envpol.2020.114465

50. Sciomer S, Moscucci F, Magrì D, Badagliacca R, Piccirillo G, Agostoni P. SARSCoV-2 spread in Northern Italy: what about the pollution role? Environ Monit Assess. 2020;192(6). doi:10.1007/s10661-020-08317-y

51. Frontera A, Cianfanelli L, Vlachos K, Landoni G, Cremona G. Severe air pollution links to higher mortality in COVID-19 patients: the "double-hit" hypothesis. J Infect. Published online May 21, 2020. doi:10.1016/j.jinf.2020.05.031

52. Natale F, Ghio D, Tarchi D, Goujon A, Conte A. COVID-19 Cases and Case Fatality Rate by Age. European Commission; 2020:18
53. Bonafè M, Prattichizzo F, Giuliani A, Storci G, Sabbatinelli J, Olivieri F. Inflammaging: Why older men are the most susceptible to SARS-CoV-2 complicated outcomes. Cytokine \& Growth Factor Reviews. Published online May 3, 2020. doi:10.1016/j.cytogfr.2020.04.005

54. Nikolich-Zugich J, Knox KS, Rios CT, Natt B, Bhattacharya D, Fain MJ. SARSCoV-2 and COVID-19 in older adults: what we may expect regarding pathogenesis, immune responses, and outcomes. Geroscience. 2020;42(2):505-514. doi:10.1007/ s11357-020-00186-0

55. Fougère $B$, Landkocz $\mathrm{Y}$, Lepers $\mathrm{C}$, et al. Influence of aging in the modulation of epigenetic biomarkers of carcinogenesis after exposure to air pollution. Exp Gerontol. 2018;110:125-132. doi:10.1016/j.exger.2018.05.018

56. Simoni M, Baldacci S, Maio S, Cerrai S, Sarno G, Viegi G. Adverse effects of outdoor pollution in the elderly. Journal of Thoracic Disease. 2015;7(1):34-45-45. doi:10.3978/j.issn.2072-1439.2014.12.10

57. Moccia F, Gerbino A, Lionetti V, et al. COVID-19-associated cardiovascular morbidity in older adults: a position paper from the Italian Society of Cardiovascular Researches. Geroscience. Published online May 20, 2020. doi:10.1007/s11357-020-00198-w

58. Madrigano J, Kloog I, Goldberg R, Coull BA, Mittleman MA, Schwartz J. Long-term exposure to PM2.5 and incidence of acute myocardial infarction. Environ Health Perspect. 2013;121(2):192-196. doi:10.1289/ehp.1205284

59. Clark NA, Demers PA, Karr CJ, et al. Effect of early life exposure to air pollution on development of childhood asthma. Environ Health Perspect. 2010;118(2):284-290. doi:10.1289/ehp.0900916

60. Guarnieri M, Balmes JR. Outdoor air pollution and asthma. The Lancet. 2014;383(9928):1581-1592. doi:10.1016/S0140-6736(14)60617-6 